Article

\title{
Single-Valued Neutrosophic Linguistic Logarithmic Weighted Distance Measures and Their Application to Supplier Selection of Fresh Aquatic Products
}

\author{
Jiefeng Wang ${ }^{1}$, Shouzhen Zeng ${ }^{1,2, *}$ and Chonghui Zhang ${ }^{3, *}$ \\ 1 School of Business, Ningbo University, Ningbo 315211, China; wangjiefeng@nbu.edu.cn \\ 2 School of Management, Fudan University, Shanghai 200433, China \\ 3 College of Statistics and Mathematics, Zhejiang Gongshang University, Hangzhou 310018, China \\ * Correspondence: zengshouzhen@nbu.edu.cn (S.Z.); zhangch1988@zjgsu.edu.cn (C.Z.)
}

Received: 19 February 2020; Accepted: 11 March 2020; Published: 17 March 2020

\begin{abstract}
A single-valued neutrosophic linguistic set (SVNLS) is a popular fuzzy tool for describing deviation information in uncertain complex situations. The aim of this paper is to study some logarithmic distance measures and study their usefulness in multiple attribute group decision making (MAGDM) problems within single-valued neutrosophic linguistic (SVNL) environments. For achieving the purpose, SVNL weighted logarithmic averaging distance (SVNLWLAD) and SVNL ordered weighted logarithmic averaging distance (SVNLOWLAD) measures are firstly developed based on the logarithmic aggregation method. Then, the SVNL combined weighted logarithmic averaging distance (SVNLCWLAD) measure is presented by unifying the advantages of the previous SVNLWLAD and SVNLOWLAD measures. Moreover, a new MAGDM model by utilizing the SVNLCWLAD measure is presented under SVNL environments. Finally, a supplier selection for fresh aquatic products is taken as a case to illustrate the performance of the proposed framework.
\end{abstract}

Keywords: single-valued neutrosophic linguistic set; combined weighted; logarithmic distance measure; supplier selection; fresh aquatic products; MAGDM

\section{Introduction}

There are more and more vagueness and uncertainties in multiple attribute group decision making (MAGDM) problems, with the increasing complex of the evaluated objects. Therefore, researching a suitable fuzzy tool for depicting such uncertain information is a key issue in MAGDM problems. Up to now, numerous tools, such as the linguistic term set [1,2], intuitionistic fuzzy set (IFS) [3], hesitant fuzzy set [4], Pythagorean fuzzy set [5], single-valued neutrosophic set [6] and q-rung orthopair fuzzy set [7] arise at the historic moment, which greatly reduce the burden of decision makers for expressing the assessment of the attributes during the decision-making process.

Recently, Ye [8] proposed the single-valued neutrosophic linguistic set (SVNLS), which has been broadly used to handle uncertainties or vagueness under complex decision-making situations. The distinctive advantage of the SVNLS is that it combines the features of the linguistic set [2] and the single-valued neutrosophic set [5], therefore it can describe the uncertain information comprehensively and reasonably more concretely and accurately. Moreover, compared with the previous methods, such as the Pythagorean linguistic set [9] and the intuitionistic linguistic set [10], the SVNLS can overcome their defects, as it uses three elements (i.e., truth, indeterminacy and falsity) to express uncertainties of evaluated objects. So far, the SVNLS has gained increasing attention from researchers. For example, Ye [8] adapted the classic TOPSIS into SVNL environments and explored its performance in selecting suppliers. Guo and Sun [11] presented a method based on the prospect theory for decision 
making with SVNL information. Zhao et al. [12] introduced some SVNL induced Choquet integral aggregation operators and studied their usefulness in MAGDM. Ji et al. [13] studied the features of SVNLS and utilized it to express the uncertainties of outsourcing provider. Wang et al. [14] investigated the Maclaurin symmetric mean method for aggregating SVNL information. Chen et al. [15] presented an ordered aggregation distance measure for SVNLSs, and developed the SVNL ordered weighted averaging distance (SVNLOWAD) measure. Based on the work of Chen et al. [15], Cao et al. [16] developed a SVNL combined aggregation distance measure. Garg and Nancy [17] studied the SVNL prioritized weighted operators and used them to handle the priority relationship among attributes.

In the field of MAGDM, distance measures are often utilized to calculate the deviations between an ideal collection and the potential alternatives. Wherein the construction of distance plays a decisive role for the measurement, the weighted distance measures, including the weighted Hamming, the weighted Euclidean and the weighted Minkowski distances, are some of the most used distance measures [18]. Recently, the ordered weighted averaging distance (OWAD) measure introduced by Merigó and Gil-Lafuente [19] has become a very popular tool and gained lots of extensions, such as the linguistic OWAD [20], the induced OWAD [21,22], Heavy OWAD [23], continuous OWAD [24] intuitionistic fuzzy OWAD [25], hesitant fuzzy OWAD [26,27] and Pythagorean fuzzy OWAD measures [28,29]. More recently, Alfaro-García et al. [30] proposed a new extension of the OWAD measure, on the basis of the logarithmic aggregation method [31,32]; the result is the ordered weighted logarithmic averaging distance (OWLAD) measure. Motivated by the OWLAD, Alfaro-García et al. [33] further developed the induced OWLAD (IOWLAD) measure.

This study proposes some SVNL weighted logarithmic distance measures for highlighting the theory and application of SVNLS. Firstly, we present the SVNL weighted logarithmic averaging distance (SVNLWLAD) measure and SVNL ordered weighted logarithmic averaging distance (SVNLOWLAD) measures. Then, the SVNL logarithmic combined weighted logarithmic averaging distance (SVNLCWLAD) measure is proposed, by unifying the main advantages of the SVNLWAD and the SVNLOWLAS measures. Thus, it can weight both the SVNL deviations as well as their ordered positions, which enables its capability to overcome the limitation of the previous SVNLWLAD and SVNLOWLAD measures. The main properties and particular cases of the SVNLCWLAD are also studied. A MAGDM method based on the proposed SVNLCWLAD is formulated and its application are verified by a supplier selection problem.

The rest of this study is set out below: Section 2 reviews the backgrounds of SVNLS and the OWLAD measure. Section 3 proposes three SVNL weighted logarithmic distances, and provides some of their main properties and families. Section 4 gives a MAGDM approach based on the SVNLCWLAD measure. In Section 5, the application and merits of the presented method are discussed through a mathematical example and comparison. Finally, Section 6 summarizes the main conclusions.

\section{Preliminaries}

In this section, some concepts regarding the issues of the SVNLS, the OWAD and the OWALD measures are briefly reviewed.

\subsection{The Single-Valued Neutrosophic Set (SVNS)}

On the basis of the neutrosophic set [34], Ye [5] introduced the definition of the single-valued neutrosophic set (SVNS) for improving computational efficiency.

Definition 1 [5]. A single-valued neutrosophic set (SVNS) $\eta$ in a finite set $X$ denoted by a mathematical form:

$$
\eta=\left\{\left\langle x, T_{\eta}(x), I_{\eta}(x), F_{\eta}(x)\right\rangle \mid x \in X\right\}
$$

where $T_{\eta}(x), I_{\eta}(x)$ and $F_{\eta}(x)$ represent the truth, the indeterminacy and the falsity-membership functions, respectively, and satisfy: 


$$
0 \leq T_{Z}(x), I_{Z}(x), F_{Z}(x) \leq 1,0 \leq T_{Z}(x)+I_{Z}(x)+F_{Z}(x) \leq 3
$$

For convenience, the triplet $\left(T_{\eta}(x), I_{\eta}(x), F_{\eta}(x)\right)$ is called the single-valued neutrosophic number (SVNN) and simply denoted as $\eta=\left(T_{\eta}, I_{\eta}, F_{\eta}\right)$.

\subsection{The Linguistic Set}

Definition 2 [2]. Let $S=\left\{s_{\alpha} \mid \alpha=1, \ldots, t\right\}$ be a finitely ordered discrete set, where $s_{\alpha}$ denotes a linguistic term and $l$ is an odd number. For example, taking $t=7$, then $S=$ $\left\{s_{1}=\right.$ extremely poor, $s_{2}=$ very poor,$s_{3}=$ poor,$s_{4}=$ fair,$s_{5}=$ good, $s_{6}=$ very good, $s_{7}=$ extremely good $\}$. For actual application, we shall extend the discrete set $S$ into a continuous set $\bar{S}=\left\{s_{\alpha} \mid \alpha \in R\right\}$ for avoiding information loss. For any linguistic terms $s_{\alpha}, s_{\beta} \in \bar{S}$, they shall satisfy following operational laws [35]:

(1) $s_{\alpha} \oplus s_{\beta}=s_{\alpha+\beta} ;$

(2) $\mu s_{\alpha}=s_{\mu \alpha}, \mu \geq 0$;

\subsection{The Single-Valued Neutrosophic Linguistic Set (SVNLS)}

Definition 3 [8]. A single-valued neutrosophic linguistic set (SVNLS) $\phi$ in $X$ is defined as:

$$
\phi=\left\{\left\langle x,\left[s_{\theta(x)},\left(T_{\phi}(x), I_{\phi}(x), F_{\phi}(x)\right)\right]\right\rangle \mid x \in X\right\}
$$

where $s_{\theta(x)} \in \bar{S}$, the functions $T_{\phi}(x), I_{\phi}(x)$ and $F_{\phi}(x)$ denote the truth, indeterminacy and falsity-membership, respectively, and they have the following constraint:

$$
0 \leq T_{\phi}(x), I_{\phi}(x), F_{\phi}(x) \leq 1,0 \leq T_{\phi}(x)+I_{\phi}(x)+F_{\phi}(x) \leq 3 .
$$

In addition, $x=\left\langle s_{\theta(x)},\left(T_{x}, I_{x}, F_{x}\right)\right\rangle$ is called the SVNL number (SVNLN) for computational convenience. Let $x_{i}=\left\langle s_{\theta\left(x_{i}\right)},\left(T_{x_{i}}, I_{x_{i}}, F_{x_{i}}\right)\right\rangle(i=1,2)$ be two SVNLNs and $\lambda>0$, then

(1) $x_{1} \oplus x_{2}=\left\langle s_{\theta\left(x_{1}\right)+\theta\left(x_{2}\right)},\left(T_{x_{1}}+T_{x_{2}}-T_{x_{1}} * T_{x_{2}}, I_{x_{1}} * I_{x_{2}}, F_{x_{1}} * F_{x_{2}}\right)\right\rangle$;

(2) $\lambda x_{1}=\left\langle s_{\lambda \theta\left(x_{1}\right)},\left(1-\left(1-T_{x_{1}}\right)^{\lambda},\left(I_{x_{1}}\right)^{\lambda},\left(F_{x_{1}}\right)^{\lambda}\right)\right\rangle$;

(3) $x_{1}^{\lambda}=\left\langle s_{\theta^{\lambda}\left(x_{1}\right)},\left(\left(T_{x_{1}}\right)^{\lambda}, 1-\left(1-I_{x_{1}}\right)^{\lambda}, 1-\left(1-F_{x_{1}}\right)^{\lambda}\right)\right\rangle$.

Definition 4 [8]. Let $x_{i}=\left\langle s_{\theta\left(x_{i}\right)},\left(T_{x_{i}}, I_{x_{i}}, F_{x_{i}}\right)\right\rangle(i=1,2)$ be SVNLNs and $p>0$, then the distance measure between $x_{1}$ and $x_{2}$ is given by the mathematical form:

$$
d_{S V N L}\left(x_{1}, x_{2}\right)=\left[\left|\theta\left(x_{1}\right) T_{x_{1}}-\theta\left(x_{2}\right) T_{x_{2}}\right|^{p}+\left|\theta\left(x_{1}\right) I_{x_{1}}-\theta\left(x_{2}\right) I_{x_{2}}\right|^{p}+\left|\theta\left(x_{1}\right) F_{x_{1}}-\theta\left(x_{2}\right) F_{x_{2}}\right|^{p}\right]^{1 / p}
$$

On the basis of Definition 3, the SVNL weighted distance (SVNLWD) measure is formed in Equation (6), by assigning different levels of importance for the individual deviations.

$$
\operatorname{SVNLWD}\left(\left(x_{1}, y_{1}\right), \ldots,\left(x_{n}, y_{n}\right)\right)=\sum_{j=1}^{n} w_{j} d_{S V N L}\left(x_{j}, y_{j}\right),
$$

where the relative weight vector $W$ satisfies $w_{j} \in[0,1]$ and $\sum_{j=1}^{n} w_{j}=1$. 


\subsection{The Ordered Weighted Logarithmic Averaging Distance (OWLAD) Measure}

Motivated by the ordered weighted averaging (OWA) operator [36], Merigó and Gil-Lafuente [19] introduced the OWAD measure.

Definition 5 [19]. Let $U=\left\{u_{1}, u_{2}, \ldots, u_{n}\right\}$ and $V=\left\{v_{1}, v_{2}, \ldots, v_{n}\right\}$ be two crisp sets, $d_{i}=\left|u_{i}-v_{i}\right|$ be the distance between $u_{i}$ and $v_{i}$, then the OWAD measure is defined as:

$$
O W A D(U, V)=O W A D\left(d_{1}, d_{2}, \ldots, d_{n}\right)=\sum_{j=1}^{n} \omega_{j} d_{\sigma(j)}
$$

where $d_{\sigma(j)}(j=1,2, \ldots, n)$ is the reorder values of $d_{j}(j=1,2, \ldots, n)$ such that $d_{\sigma(1)} \geq d_{\sigma(2)} \geq \cdots d_{\sigma(n)}$. The relative weight vector of the OWAD is $\omega=\left\{\omega_{j} \mid \sum_{i=1}^{n} \omega_{j}=1, \quad 0 \leq \omega_{j} \leq 1\right\}$.

On the basis of the recent research of Zhou and Chen [31] and the OWAD measure, Alfaro-García et al. [30] introduced the OWLAD measure.

Definition 6 [30]. Let $U=\left\{u_{1}, u_{2}, \ldots, u_{n}\right\}$ and $V=\left\{v_{1}, v_{2}, \ldots, v_{n}\right\}$ be two crisp sets, $d_{i}=\left|u_{i}-v_{i}\right|$ be the distance between $u_{i}$ and $v_{i}$, then the OWLAD measure is defined as:

$$
O W L A D(U, V)=O W A D\left(d_{1}, d_{2}, \ldots, d_{n}\right)=\exp \left(\sum_{j=1}^{n} \omega_{j} \ln \left(d_{\sigma(j)}\right)\right)
$$

Alfaro-García et al. [30] studied desired properties of the OWLAD measure, such as boundedness, commutativity, idempotency and monotonicity. They also explored its different families and found that it includes many distance measures. However, the OWLAD is generally designed for aggregating crisp variables and cannot be used to handle SVNL information. What's more, it can only account for the weights of ordered deviations, but fails to consider the importance of the individual data. Therefore, we shall develop a new distance measure for overcoming the limitations of the OWLAD within SVNL environments.

\section{SVNL Weighted Logarithmic Distance Measures}

\subsection{SVL Weighted Logarithmic Averaging Distance (SVNLWLAD) Measure}

The SVNLWLAD measure is a new SVNL distance measure that utilizes the optimal logarithmic aggregation for handling SVNL deviations. It can consider the importance of the aggregated individual distances.

Definition 7. Let $d_{S V N L}\left(x_{j}, y_{j}\right)$ be the distance between two $x_{j}, y_{j}(j=1, \ldots, n)$ defined in Equation (5), then the SVNLWLAD measure is defined as:

$$
\operatorname{SVNLWLAD}\left(\left(x_{1}, y_{1}\right), \ldots,\left(x_{n}, y_{n}\right)\right)=\exp \left\{\sum_{j=1}^{n} w_{j} \ln \left(d_{S V N L}\left(x_{j}, y_{j}\right)\right)\right\}
$$

where $w_{j}$ is the weight of the distance $d_{S V N L}\left(x_{j}, y_{j}\right)$ with $\sum_{j=1}^{n} w_{j}=1$ and $w_{j} \in[0,1]$.

Example 1. Let $X=\left(x_{1}, x_{2}, x_{3}, x_{4}, x_{5}\right)==\left(\left\langle s_{2},(0.6,0.5,0.1)\right\rangle,\left\langle s_{5},(0.6,0.3,0.5)\right\rangle,\left\langle s_{4},(0.7,0.2,0.1)\right\rangle\right.$, $\left.\left\langle s_{3},(0.9,0.1,0.6)\right\rangle,\left\langle s_{4},(0.3,0.1,0.3)\right\rangle\right)$ and $Y=\left(y_{1}, y_{2}, y_{3}, y_{4}, y_{5}\right)=\left(\left\langle s_{4},(0.2,0.7,0)\right\rangle,\left\langle s_{6},(0.3,0.7,0.1)\right\rangle\right.$, $\left.\left\langle s_{7},(0.6,0.4,0.5)\right\rangle,\left\langle s_{1},(0.1,0.7,0.2)\right\rangle,\left\langle s_{3},(0.1,0.5,0.6)\right\rangle\right)$ be two SVNLSs defined in $S=$ 
$\left\{s_{1}, s_{2}, s_{3}, s_{4}, s_{5}, s_{6}, s_{7}\right\}$. The weighting vector is supposed to be $w=(0.15,0.25,0.25,0.15,0.2)^{T}$. Then the computational process through the SVNLWLAD can be displayed as follows:

(1) Calculate the individual distances $d_{S V N L}\left(x_{i}, y_{i}\right)(i=1,2, \ldots, 5)$ according to Equation (5) (let $\left.p=1\right)$ :

$$
\begin{aligned}
& d_{S V N L}\left(x_{1}, y_{1}\right)=|2 \times 0.6-4 \times 0.2|+|2 \times 0.5-4 \times 0.7|+|2 \times 0.1-4 \times 0|=2.4, \\
& d_{S V N L}\left(x_{2}, y_{2}\right)=|5 \times 0.6-6 \times 0.3|+|5 \times 0.3-6 \times 0.7|+|5 \times 0.5-6 \times 0.1|=5.8, \\
& d_{S V N L}\left(x_{3}, y_{3}\right)=|4 \times 0.7-7 \times 0.6|+|4 \times 0.2-7 \times 0.4|+|4 \times 0.1-7 \times 0.5|=6.5, \\
& d_{S V N L}\left(x_{4}, y_{4}\right)=|3 \times 0.9-1 \times 0.1|+|3 \times 0.1-1 \times 0.7|+|3 \times 0.6-1 \times 0.2|=4.2, \\
& d_{S V N L}\left(x_{5}, y_{5}\right)=|4 \times 0.3-3 \times 0.1|+|4 \times 0.1-3 \times 0.5|+|4 \times 0.3-3 \times 0.6|=2.6 .
\end{aligned}
$$

(2) Utilize the SVNLWLAD defined in Equation (9) to aggregate the individual distances:

$$
\begin{aligned}
& \operatorname{SVNLWLAD}\left(\left(x_{1}, y_{1}\right), \ldots,\left(x_{5}, y_{5}\right)\right)=\exp \left\{\sum_{j=1}^{n} w_{j} \ln \left(d_{S V N L}\left(x_{j}, y_{j}\right)\right)\right\} \\
& =\exp \left\{\sum_{j=1}^{n}(0.15 \times \ln (2.4)+0.25 \times \ln (5.8)+0.25 \times \ln (6.5)+0.15 \times \ln (4.2)+0.2 \times \ln (2.6)\}\right. \\
& =4.2423
\end{aligned}
$$

\subsection{SVL Ordered Weighted Logarithmic Averaging Distance (SVNLOWLAD) Measure}

The SVNLOWLAD operator is a useful extension of the OWLAD measure which uses SVNL information. Moreover, it can be seen as a generalization of the SVNLWLAD measure, which is characterized by its ordered mechanism of the aggregated arguments. This mechanism provides the opportunity to consider complex attitudes in the decision-making processes, as well as to handle the logarithmic deviations.

Definition 8. Let $d_{S V N L}\left(x_{j}, y_{j}\right)$ be the distance between SVNLNs $x_{j}, y_{j}(j=1, \ldots, n)$ defined in Equation (5), then the SVNLOWLAD is defined as:

$$
\operatorname{SVNLOWLAD}\left(\left(x_{1}, y_{1}\right), \ldots,\left(x_{n}, y_{n}\right)\right)=\exp \left\{\sum_{j=1}^{n} \omega_{j} \ln \left(d_{S V N L}\left(x_{\sigma(j)}, y_{\sigma(j)}\right)\right)\right\},
$$

where $d_{S V N L}\left(x_{\sigma(j)}, y_{\sigma(j)}\right)(j=1,2, \ldots, n)$ is the reorder values of $d_{S V N L}\left(x_{j}, y_{j}\right)$ such that $d_{S V N L}\left(x_{\sigma(1)}, y_{\sigma(1)}\right) \geq \ldots . \geq d_{S V N L}\left(x_{\sigma(n)}, y_{\sigma(n)}\right)$. The associated weight vector of the SVNLOWLAD is $\omega=\left(\omega_{1}, \omega_{2}, \ldots, \omega_{\mathrm{n}}\right)^{\mathrm{T}}$ with $\sum_{j=1}^{n} \omega_{j}=1$ and $\omega_{j} \in[0,1]$.

Similar to the OWLAD measure, the proposed SVNLOWLAD measure has the properties of idempotency, commutativity, monotonicity, boundedness and non-negativity. The proofs of these properties are trivial and thus omitted.

Example 2. (Continuing Example 1). Suppose the weight vector of SVNLOWLAD measure is $\omega=(0.1,0.2,0.25,0.3,0.15)^{T}$. Then, the computational process based on the SVNLOWLAD is displayed as follows:

(1) Compute the individual distances $d_{S V N L}\left(x_{i}, y_{i}\right)(i=1,2, \ldots, 5)$ according to Equation (5) (obtained from example 1):

$$
\begin{gathered}
d_{S V N L}\left(x_{1}, y_{1}\right)=2.4, d_{S V N L}\left(x_{2}, y_{2}\right)=5.8, d_{S V N L}\left(x_{3}, y_{3}\right)=6.5 \\
d_{S V N L}\left(x_{4}, y_{4}\right)=4.2, d_{S V N L}\left(x_{5}, y_{5}\right)=2.6
\end{gathered}
$$


(2) Rank the $d_{S V N L}\left(x_{i}, y_{i}\right)(i=1,2, \ldots, 5)$ in decreasing order:

$$
\begin{aligned}
d_{S V N L}\left(x_{\sigma(1)}, y_{\sigma(1)}\right)= & d_{S V N L}\left(x_{3}, y_{3}\right)=6.5, d_{S V N L}\left(x_{\sigma(2)}, y_{\sigma(2)}\right)=d_{S V N L}\left(x_{2}, y_{2}\right)=5.8 \\
d_{S V N L}\left(x_{\sigma(3)}, y_{\sigma(3)}\right)= & d_{S V N L}\left(x_{4}, y_{4}\right)=4.2, d_{S V N L}\left(x_{\sigma(4)}, y_{\sigma(4)}\right)=d_{S V N L}\left(x_{5}, y_{5}\right)=2.6 \\
& d_{S V N L}\left(x_{\sigma(5)}, y_{\sigma(5)}\right)=d_{S V N L}\left(x_{1}, y_{1}\right)=2.4
\end{aligned}
$$

(3) Utilize the SVNLOWLAD to aggregate the ordered distances:

$$
\begin{aligned}
& \operatorname{SVNLOWLAD}\left(\left(x_{1}, y_{1}\right), \ldots,\left(x_{5}, y_{5}\right)\right)=\exp \left\{\sum_{j=1}^{5} w_{j} \ln \left(d_{S V N L}\left(x_{\sigma(j)}, y_{\sigma(j)}\right)\right)\right\} \\
& =\exp \{0.1 \times \ln (6.5)+0.2 \times \ln (5.8)+0.25 \times \ln (4.2)+0.3 \times \ln (2.6)+0.15 \times \ln (2.4)\} \\
& =3.7266
\end{aligned}
$$

\subsection{SVL Combined Weighted Logarithmic Averaging Distance (SVNLCWLAD) Measure}

From the previous examples, we can see that the SVNLWLAD can account for the importance of input deviations, while the SVNLOWLAD considers the weights of ordered deviations, and based on this rule, it can depict some attitudes of decision makers in decision making. However, the SVNLWLAD does not have the function of orderly aggregation, while the SVNLOWLAD cannot integrate the importance of attributes that the SVNLWLAD can. To overcome these limitations, we shall develop a new distance measure that can combine the advantages of the SVNLWLAD and the SVNLOWLAD measures.

Definition 9. Let $x_{j}, y_{j}(j=1, \ldots, n)$ be the two collections of SVNLNs. If

$$
\operatorname{SVNLCWLAD}\left(\left(x_{1}, y_{1}\right), \ldots,\left(x_{n}, y_{n}\right)\right)=\exp \left\{\sum_{j=1}^{n} \omega_{j} \ln \left(d_{S V N L}\left(x_{\sigma(j)}, y_{\sigma(j)}\right)\right)\right\},
$$

then the SVNLCWLAD is called the SVNL combined weighted logarithmic averaging distance measure. The integrated weights $\omega_{j}$ is defined as:

$$
\omega_{j}=\gamma \omega_{j}+(1-\gamma) w_{\sigma(j)}
$$

where $w_{j}$ is the weight of $d_{S V N L}\left(x_{j}, y_{j}\right)(j=1,2, \ldots, n)$ with $\sum_{j=1}^{n} w_{j}=1$ and $w_{j} \in[0,1]$, and the other $\omega_{j}$, is the associated weight of SVNLOWLAD satisfying $\sum_{j=1}^{n} \omega_{j}=1$ and $\omega_{j} \in[0,1]$, parameter $\gamma$ is real parameter and meeting $\gamma \in[0,1]$.

Obviously, the SVNLCWLAD is generalized to the SVNLOWLAD and SVNLWLAD, when $\gamma=1$ and $\lambda=0$, respectively. Following the combined operational rules, the SVNLWLAD can be regarded as a combination of the SVNLOWLAD and SVNLWLAD measures:

$$
\begin{aligned}
& \operatorname{SVNLCWLAD}\left(\left(x_{1}, y_{1}\right), \ldots,\left(x_{n}, y_{n}\right)\right)= \\
& \exp \left(\left\{\gamma \sum_{j=1}^{n} \omega_{j} \ln \left(d_{S V N L}\left(x_{\sigma(j)}, y_{\sigma(j)}\right)\right)\right\}+\left\{(1-\gamma) \sum_{j=1}^{n} w_{j} \ln \left(d_{S V N L}\left(x_{j}, y_{j}\right)\right)\right\}\right)
\end{aligned}
$$

Example 3. (Continuing Examples 1 and 2). Let $\gamma=0.6$ and based on the available information obtained in the examples 1 and 2, we can compute the integrated weights $\Phi_{j}$ according to Equation (12): 


$$
\begin{gathered}
\omega_{1}=0.6 \times 0.1+(1-0.6) \times 0.25=0.16, \\
\omega_{2}=0.6 \times 0.2+(1-0.6) \times 0.25=0.22, \\
\omega_{3}=0.6 \times 0.25+(1-0.6) \times 0.15=0.21, \omega_{4}=0.6 \times 0.3+(1-0.6) \times 0.2=0.26, \\
\omega_{5}=0.6 \times 0.15+(1-0.6) \times 0.15=0.15 .
\end{gathered}
$$

Perform the below aggregation, utilizing the SVNLCWLAD measure defined in Equation (11):

$$
\begin{aligned}
& \operatorname{SVNLCWLAD}\left(\left(x_{1}, y_{1}\right), \ldots,\left(x_{5}, y_{5}\right)\right)=\exp \left\{\sum_{j=1}^{5} \omega_{j} \ln \left(d_{S V N L}\left(x_{\sigma(j)}, y_{\sigma(j)}\right)\right)\right\} \\
& =\exp \{0.16 \times \ln (6.5)+0.22 \times \ln (5.8)+0.21 \times \ln (4.2)+0.26 \times \ln (2.6)+0.15 \times \ln (2.4)\} \\
& =3.9249
\end{aligned}
$$

We can also apply the SVNLCWLAD measure given in Equation (13) to illustrate the aggregation:

$$
\begin{aligned}
& S V N L C W L A D=\exp \left(\left\{\gamma \sum_{j=1}^{n} \omega_{j} \ln \left(d_{S V N L}\left(x_{\sigma(j)}, y_{\sigma(j)}\right)\right)\right\}+\left\{(1-\gamma) \sum_{j=1}^{n} w_{j} \ln \left(d_{S V N L}\left(x_{j}, y_{j}\right)\right)\right\}\right) \\
& =\exp (0.6 \times 1.3155+(1-0.6) \times 1.4451) \\
& =3.9249
\end{aligned}
$$

Apparently, the same results are obtained by both methods. On the other hand, following the aforementioned examples, we can see that the SVNLCWLAD combines both features of the SVNLOWLAD and the SVNLWLAD measures. Therefore, it can account for the importance of the deviations as well as highlights the ordered aggregation mechanism. Moreover, it is more convenient for application, as people can set parameters flexibly according to actual needs or their interests.

Furthermore, we can achieve some interesting SVNL distance measures, by designing the parameter $\gamma$ and the weight vector in the SVNLCWLAD measure, for example:

- The SVNLOWLAD and SVNLWLAD measures are obtained when $\gamma=1$ and $\lambda=0$, respectively. Moreover, the more lager $\gamma$, the more importance focused on the SVNLOWLAD.

- If $w=(1,0,0, \ldots, 0)^{T}$, then max-SVNLCWLAD measure is formed.

- If $w=(0, \ldots, 0,1)^{T}$, then the min-SVNLCWLAD is rendered.

- The step-SVNLCWLAD measure is obtained by designing $w_{1}=\cdots=w_{k-1}=0, w_{k}=1$ and $w_{k+1}=\cdots=w_{n}=0$.

- Based on the analysis provided in recent literature [30,33,37-40], more particular cases of the SVNLCWLAD, such as the Centered-SVNLCWLAD, Median-SVNLCWLAD and the Olympic-SVNLCWLAD measures, can be created.

According to the properties of the OWLAD measure, it is clear that the SVNLCWLAD satisfies the desirable properties of monotonicity, idempotency, boundedness and:

(1) Monotonicity: If $d_{S V N L}\left(x_{i}, y_{i}\right) \geq d_{S V N L}\left(x^{\prime}{ }_{i}, y^{\prime}{ }_{i}\right)$ for $i=1,2, \ldots, n$, then

$$
\operatorname{SVNLCWLAD}\left(\left(x_{1}, y_{1}\right), \ldots,\left(x_{n}, y_{n}\right)\right) \geq \operatorname{SVNLCWLAD}\left(\left(x^{\prime}{ }_{1}, y^{\prime}{ }_{1}\right), \ldots,\left(x_{n}^{\prime}, y^{\prime}{ }_{n}\right)\right)
$$

(2) Idempotency: If $d_{S V N L}\left(x_{i}, y_{i}\right)=d$ for $i=1,2, \ldots, n$, then

$$
\operatorname{SVNLCWLAD}\left(\left(x_{1}, y_{1}\right), \ldots,\left(x_{n}, y_{n}\right)\right)=d
$$

(3) Commutativity: If $\left(\left(x_{1}, x^{\prime}{ }_{1}\right), \ldots,\left(x_{n}, x_{n}^{\prime}\right)\right)$ is any permutation of $\left(\left(y_{1}, y^{\prime}{ }_{1}\right), \ldots,\left(y_{n}, y^{\prime}{ }_{n}\right)\right)$, then

$$
\operatorname{SVNLCWLAD}\left(\left(x_{1}, x^{\prime}{ }_{1}\right), \ldots,\left(x_{n}, x_{n}^{\prime}\right)\right)=\operatorname{SVNLCWLAD}\left(\left(y_{1}, y_{1}^{\prime}{ }_{1}\right), \ldots,\left(y_{n}, y_{n}^{\prime}{ }_{n}\right)\right)
$$


(4) Boundedness: Let $d_{\min }=\min _{i}\left(d\left(y_{i}, y_{i}^{\prime}\right)\right)$ and $d_{\max }=\max _{i}\left(d\left(y_{i}, y_{i}^{\prime}\right)\right)$, then

$$
d_{\min } \leq \operatorname{SVNLCWLAD}\left(\left(y_{1}, y_{1}^{\prime}{ }_{1}\right), \ldots,\left(y_{n}, y_{n}^{\prime}\right)\right) \leq d_{\max }
$$

In addition, we can provide a more generalized SVNL combined weighted logarithmic distance measure, by using the generalized mean method [41]; the result is the generalized SVNLCWLAD (GSVNLCWLAD) measure:

$$
\operatorname{GSVNLCWLAD}\left(\left(x_{1}, y_{1}\right), \ldots,\left(x_{n}, y_{n}\right)\right)=\exp \left\{\left(\sum_{j=1}^{n} \omega_{j} \ln \left(d_{S V N L}\left(x_{\sigma(j)}, y_{\sigma(j)}\right)\right)^{\lambda}\right)^{1 / \lambda}\right\}
$$

where $\lambda$ is a parameter that meets $\lambda \in(-\infty,+\infty)-\{0\}$. Some representative cases of the GSVNLCWALD measure can be determined from the variation of parameter $\lambda$, for example, the SVNLCWLAD is formed when $\lambda=1$, the SVNL combined weighted logarithmic quadratic distance (SVNLCWLQD) is obtained if $\lambda=2$, and the SVNL combined weighted logarithmic harmonic distance (SVNLCWLHD) is rendered if $\lambda=-1$. Other more special families of the GSVNLCWLAD measure can be analyzed by using similar methods, provided in reference [41-43].

\section{Application in MAGDM}

The SVNLCWLAD is applicable to decision making, pattern recognition, data analysis, financial investment, social management, and many other fields. In this paper, we present its application in MAGDM problems under SVNL environments. Consider a MAGDM problem, which includes $m$ different alternatives denoted as $B_{1}, B_{2}, \ldots, B_{m}$ and several experts invited to evaluate $n$ finite attributes $A_{1}, A_{2}, \ldots, A_{n}$. The weight vector for these attributes is represented by $w=\left(w_{1}, w_{2}, \ldots, w_{n}\right)^{T}$ such that $w_{j} \in[0,1]$ and $\sum_{j=1}^{n} w_{j}=1$. Following the available information, the general procedure for MAGDM can be summarized below.

Step 1: Let each expert $e_{q}(q=1,2, \ldots, t)$ (whose weight is $\tau_{q}$, with $\tau_{q} \geq 0$ and $\sum_{q=1}^{t} \tau_{q}=1$ ) expresses his or her assessment for different alternatives under given attributes by means of SVNLNs, thus formulate SVNL individual decision matrix $R^{q}=\left(r_{i j}^{(q)}\right)_{m \times n}$.

Step 2: The collective decision matrix $R=\left(r_{i j}\right)_{m \times n}$ is calculated by using the SVNL weighted average (SVNLWA) operator [8] to aggregate individual assessment, where $r_{i j}=\sum_{q=1}^{t} \tau_{q} r_{i j}^{(q)}$.

Step 3: Set the ideal performances for each attribute to construct the ideal scheme (Table 1).

Table 1. Ideal scheme.

\begin{tabular}{ccccc}
\hline & $A_{1}$ & $A_{2}$ & $\cdots$ & $A_{n}$ \\
\hline$I$ & $I_{1}$ & $I_{2}$ & $\ldots$ & $I_{n}$ \\
\hline
\end{tabular}

Step 4: Apply the SVNLCWLAD measure to compute the distances between the alternative $B_{i}(i=1,2, \ldots, m)$ and the ideal scheme $I$ :

$$
\operatorname{SVNLCWLAD}\left(B_{i}, I\right)=\exp \left\{\sum_{j=1}^{n} \omega_{j} \ln \left(d_{S V N L}\left(r_{\sigma(i j)}, I_{\sigma(j)}\right)\right)\right\}
$$

Step 5: Sort the alternatives according to the lowest value of distance obtained in the previous step and hence, select the best one(s). 
Step 6: End.

\section{Numerical Example for Supplier Selection of Fresh Aquatic Products}

At present, China has the largest aquatic product market in the world. With economic and social development, people's awareness for the quality and safety of aquatic products are also increasing. The most important obstacle to the further development of aquatic products has shifted from the processing field to the market circulation field. The importance and urgency of the effective maintenance of the supply chain by aquatic product processing enterprises is increasingly prominent. High-quality suppliers can provide safe and fresh raw materials and high-quality products, to help enterprises expand the market and increase competitiveness [44]. With the increasing position and role of suppliers in the production of aquatic processing enterprises, the selecting suppliers of fresh aquatic products is considered to be the most important strategic decision in the aquatic product supply chain. Thus, finding an effective method for evaluating suppliers is the key issue for buyers of fresh aquatic products. In this section, we provide uses of the proposed framework for handling this problem within SVNL environments, to highlight the theory and application of the SVNLS. Four possible fresh aquatic products suppliers $B_{i}(i=1,2,3,4)$ are needed to evaluate from below attributes: $A_{1}$ : quality and safety (including product safety, quality of goods, delivery performance and fulfill the full orders); $A_{2}$ : costs (including material cost and transportation costs); $A_{3}$ : delivery level (including delivery time, responsiveness to customers and return products time); and $A_{4}$ : supply capacity (inventory amount, ability to meet delivery demand, ability to produce new raw materials and ability to receive returns products). Three experts (expert's weight $\tau=(0.37,0.30,0.33))$ utilize SVNL information to evaluate these alternatives under four attributes, where the linguistic term set is supposed to $S=\left\{s_{1}, s_{2}\right.$, $\left.s_{3}, s_{4}, s_{5}, s_{6}, s_{7}\right\}$. The results are represented by means of SVNLNs, listed in Tables $2-4$.

Table 2. Single-valued neutrosophic linguistic (SVNL) decision matrix $R^{1}$.

\begin{tabular}{ccccc}
\hline & \multicolumn{2}{c}{$A_{1}$} & $A_{2}$ & $A_{3}$ \\
\hline$B_{1}$ & $\left\langle s_{4}^{(1)},(0.6,0.1,0.2)\right\rangle$ & $\left\langle s_{6}^{(1)},(0.6,0.1,0.2)\right\rangle$ & $\left\langle s_{5}^{(1)},(0.7,0.0,0.1)\right\rangle$ & $\left\langle s_{3}^{(1)},(0.3,0.1,0.2)\right\rangle$ \\
\hline$B_{2}$ & $\left\langle s_{5}^{(1)},(0.6,0.1,0.2)\right\rangle$ & $\left\langle s_{3}^{(1)},(0.6,0.2,0.4)\right\rangle$ & $\left\langle s_{6}^{(1)},(0.6,0.1,0.2)\right\rangle$ & $\left\langle s_{4}^{(1)},(0.5,0.2,0.2)\right\rangle$ \\
\hline$B_{3}$ & $\left\langle s_{4}^{(1)},(0.5,0.2,0.3)\right\rangle$ & $\left\langle s_{5}^{(1)},(0.3,0.5,0.2)\right\rangle$ & $\left\langle s_{4}^{(1)},(0.3,0.2,0.3)\right\rangle$ & $\left\langle s_{3}^{(1)},(0.5,0.3,0.1)\right\rangle$ \\
\hline$B_{4}$ & $\left\langle s_{5}^{(1)},(0.4,0.2,0.3)\right\rangle$ & $\left\langle s_{4}^{(1)},(0.5,0.3,0.3)\right\rangle$ & $\left\langle s_{5}^{(1)},(0.4,0.2,0.3)\right\rangle$ & $\left\langle s_{3}^{(1)},(0.3,0.2,0.5)\right\rangle$ \\
\hline
\end{tabular}

Table 3. SVNL decision matrix $R^{2}$.

\begin{tabular}{ccccc}
\hline & $A_{1}$ & $A_{2}$ & $A_{3}$ & $A_{4}$ \\
\hline$B_{1}$ & $\left\langle s_{4}^{(3)},(0.5,0.2,0.2)\right\rangle$ & $\left\langle s_{5}^{(3)},(0.7,0.2,0.1)\right\rangle$ & $\left\langle s_{4}^{(3)},(0.6,0.1,0.2)\right\rangle$ & $\left\langle s_{3}^{(3)},(0.4,0.1,0.1)\right\rangle$ \\
\hline$B_{2}$ & $\left\langle s_{4}^{(3)},(0.7,0.2,0.2)\right\rangle$ & $\left\langle s_{6}^{(3)},(0.4,0.6,0.2)\right\rangle$ & $\left\langle s_{5}^{(3)},(0.5,0.2,0.3)\right\rangle$ & $\left\langle s_{5}^{(3)},(0.7,0.2,0.1)\right\rangle$ \\
\hline$B_{3}$ & $\left\langle s_{5}^{(3)},(0.6,0.1,0.3)\right\rangle$ & $\left\langle s_{4}^{(3)},(0.3,0.6,0.2)\right\rangle$ & $\left\langle s_{6}^{(3)},(0.5,0.1,0.3)\right\rangle$ & $\left\langle s_{4}^{(3)},(0.6,0.2,0.1)\right\rangle$ \\
\hline$B_{4}$ & $\left\langle s_{6}^{(3)},(0.6,0.2,0.4)\right\rangle$ & $\left\langle s_{4}^{(3)},(0.5,0.2,0.3)\right\rangle$ & $\left\langle s_{6}^{(3)},(0.5,0.2,0.3)\right\rangle$ & $\left\langle s_{5}^{(3)},(0.2,0.1,0.6)\right\rangle$ \\
\hline
\end{tabular}


Table 4. SVNL decision matrix $R^{3}$.

\begin{tabular}{ccccc}
\hline & $A_{1}$ & $A_{2}$ & $A_{3}$ & $A_{4}$ \\
\hline$B_{1}$ & $\left\langle s_{5}^{(2)},(0.7,0.2,0.3)\right\rangle$ & $\left\langle s_{6}^{(2)},(0.6,0.3,0.3)\right\rangle$ & $\left\langle s_{4}^{(2)},(0.8,0.1,0.2)\right\rangle$ & $\left\langle s_{4}^{(2)},(0.4,0.2,0.2)\right\rangle$ \\
\hline$B_{2}$ & $\left\langle s_{6}^{(2)},(0.7,0.2,0.3)\right\rangle$ & $\left\langle s_{4}^{(2)},(0.5,0.4,0.2)\right\rangle$ & $\left\langle s_{6}^{(2)},(0.7,0.2,0.3)\right\rangle$ & $\left\langle s_{5}^{(2)},(0.6,0.2,0.2)\right\rangle$ \\
\hline$B_{3}$ & $\left\langle s_{6}^{(2)},(0.6,0.3,0.4)\right\rangle$ & $\left\langle s_{5}^{(2)},(0.4,0.4,0.1)\right\rangle$ & $\left\langle s_{6}^{(2)},(0.4,0.2,0.4)\right\rangle$ & $\left\langle s_{4}^{(2)},(0.6,0.1,0.3)\right\rangle$ \\
\hline$B_{4}$ & $\left\langle s_{6}^{(2)},(0.5,0.1,0.2)\right\rangle$ & $\left\langle s_{3}^{(2)},(0.7,0.1,0.1)\right\rangle$ & $\left\langle s_{5}^{(2)},(0.4,0.3,0.4)\right\rangle$ & $\left\langle s_{5}^{(2)},(0.3,0.1,0.6)\right\rangle$ \\
\hline
\end{tabular}

According to the individual opinions and weights of the experts, the collective decision matrix can be calculated by using the SVNLWA operator, shown in Table 5.

Table 5. Group SVNL decision matrix $R$.

\begin{tabular}{ccccc}
\hline & $A_{1}$ & $A_{2}$ & $A_{3}$ & $A_{4}$ \\
\hline$B_{1}$ & $\left\langle s_{4.33},(0.611,0.155,0.229)\right\rangle$ & $\left\langle s_{5.70},(0.633,0.180,0.186)\right\rangle$ & $\left\langle s_{4.37},(0.714,0.000,0.155)\right\rangle$ & $\left\langle s_{3.67},(0.365,0.128,0.163)\right\rangle$ \\
\hline$B_{2}$ & $\left\langle s_{4.70},(0.666,0.155,0.229)\right\rangle$ & $\left\langle s_{4.23},(0.514,0.350,0.258)\right\rangle$ & $\left\langle s_{5.70},(0.611,0.155,0.258)\right\rangle$ & $\left\langle s_{2.37},(0.602,0.200,0.162)\right\rangle$ \\
\hline$B_{3}$ & $\left\langle s_{4.96},(0.566,0.186,0.330)\right\rangle$ & $\left\langle s_{4.70},(0.335,0.491,0.159)\right\rangle$ & $\left\langle s_{5.26},(0.399,0.163,0.330)\right\rangle$ & $\left\langle s_{3.37},(0.566,0.185,0.144)\right\rangle$ \\
\hline$B_{4}$ & $\left\langle s_{5.63},(0.450,0.159,0.286)\right\rangle$ & $\left\langle s_{3.67},(0.578,0.185,0.209)\right\rangle$ & $\left\langle s_{5.30},(0.432,0.229,0.330)\right\rangle$ & $\left\langle s_{2.37},(0.271,0.129,0.561)\right\rangle$ \\
\hline
\end{tabular}

Based on the available information of the potential suppliers, the experts determine the ideal supplier that has a good performance for each attribute, shown in Table 6.

Table 6. Ideal supplier.

\begin{tabular}{ccccc}
\hline & $\boldsymbol{A}_{1}$ & $\boldsymbol{A}_{2}$ & $\boldsymbol{A}_{3}$ & $\boldsymbol{A}_{4}$ \\
\hline$I$ & $\left\langle s_{7},(1,0,0.1)\right\rangle$ & $\left\langle s_{7},(0.9,0.1,0)\right\rangle$ & $\left\langle s_{6},(0.9,0,0)\right\rangle$ & $\left\langle s_{7},(0.9,0,0.1)\right\rangle$ \\
\hline
\end{tabular}

The weighting vectors of the SVNLCWLAD measure and the attributes are considered as $\omega=(0.2,0.3,0.1,0.4)^{T}$ and $w=(0.2,0.3,0.3,0.2)^{T}$, respectively. Without loss of generality, let $\gamma=0.5$, then the distances between the alternative $B_{i}(i=1,2,3,4)$ and the ideal scheme $I$ are calculated by using the SVNLCWLAD as follows:

$$
\begin{aligned}
& \operatorname{SVNLCWLAD}\left(B_{1}, I\right)=5.0778, \operatorname{SVNLCWLAD}\left(B_{2}, I\right)=5.7808, \\
& \operatorname{SVNLCWLAD}\left(B_{3}, I\right)=6.7281, \operatorname{SVNLCWLAD}\left(B_{4}, I\right)=6.6661 .
\end{aligned}
$$

The smaller the value of the $S V N L V W L A D\left(B_{i}, I\right)$, the closer the $B_{i}$ to the ideal supplier. Therefore, the alternatives are ranked as:

$$
B_{1}>B_{2}>B_{4}>B_{3} .
$$

Hence, the best alternative is $B_{1}$.

Moreover, we apply two special cases of the SVNLCWLAD, i.e., the SVNLOWLAD and the SVNLWLAD measures, to calculate the distances between the alternatives and the ideal scheme. By the SVNLOWLAD measure, we have:

$$
\begin{aligned}
& \operatorname{SVNLOWALD}\left(B_{1}, I\right)=5.1159, \quad \operatorname{SVNLOWLAD}\left(B_{2}, I=\right)=5.7758, \\
& \operatorname{SVNLOWLAD}\left(B_{3}, I\right)=6.7648, \operatorname{SVNLOWLAD}\left(B_{4}, I\right)=6.8483 .
\end{aligned}
$$


The results obtained by the SVNLWLAD measure are:

$$
\begin{aligned}
& \operatorname{SVNLWALD}\left(B_{1}, I\right)=5.0401, \quad \operatorname{SVNLWLAD}\left(B_{2}, I=\right)=5.7857 \\
& \operatorname{SVNLWLAD}\left(B_{3}, I\right)=6.6916, \quad \operatorname{SVNLWLAD}\left(B_{4}, I\right)=6.4887 .
\end{aligned}
$$

Thus, the ranking orders based on the SVNLOWALAD and SVNLWLAD measures are $B_{1}>B_{2}>B_{3}>B_{4}$ and $B_{1}>B_{2}>B_{4}>B_{3}$, respectively. Then, we obtain the same best supplier using the SVNLCWLAD, SVNLOWLAD and SVNLWLAD measures, although all the ranking orders are different. Moreover, following the analysis in the aforementioned numerical examples, the SVNLWLAD and SVNLOWLAD measures emphasize different points in aggregation process. Generally, the SVNLWLAD accounts for the importance of attributes, while the SVNLOWLAD consider the the importance of ordered deviation. However, the SVNLCWLAD measure unifies all of features of previous methods, therefore it can overcome the limitations of the previous measures and achieve a more rational aggregation result. Furthermore, the MAGDM method based on SVNLCWLAD is more flexible than the existing MAGDM approaches based on the SVNLOWAD measure [15], as decision makers can determine some desired values of $\gamma$ in the SVNLCWLAD, according to their preferences or practical demands.

\section{Conclusions}

This paper introduces several SVNL logarithmic distance measures, including the SVNLWLAD, SVNLOWLAD and SVNLCWLAD measures. Some of their properties and particular cases are investigated. We prove that all the SVNLWLAD and SVNLOWLAD are the special cases of the SVNLCWLAD measure. Thus, the SVNLCWLAD measure combines the desired properties of SVNLWLAD and SVNLOWLAD. Moreover, it presents a more general method to handle complex situations in a more efficient and flexible way, as it can overcome the shortcomings of the existing distance measures.

Guaranteeing the quality and safety of fresh aquatic products is crucial for mankind's health and the wellbeing of fishery companies. Therefore, an appropriate supplier selection is considered as the most important strategic decision in the aquatic product supply chain. In this paper, a MAGDM approach is provided, based on the SVNLCWALD measure, and a mathematical example of selecting a fresh aquatic products problem is taken to verify its feasibility and validity. The application shows that the proposed method is effective, as the SVNLCWLAD can not only highlight the decision makers' interests through the ordered weighted mechanism, but can also integrate the importance of attributes by the weighted average function. Moreover, it provides a possibility for decision makers to flexibly select the parameter, based on the demands for the specific problem or actual interests. In addition, this study also presents an effective guideline for selecting suppliers in other industries.

In subsequent work, we will consider the application of the proposed method in other fields, such as pattern recognition, innovation management and investment selection [45-50]. We also develop some new extensions of the proposed distance measures in complex fuzzy situations.

Author Contributions: Writing-original draft preparation, S.Z.; Writing—review and editing, C.Z.; formal analysis, J.W. All authors have read and agreed to the published version of the manuscript.

Funding: This paper was supported by Major Humanities and Social Sciences Research Projects in Zhejiang Universities (no. 2018QN058), China Postdoctoral Science Foundation (no. 2019M651403), Zhejiang Province Natural Science Foundation (No. LY18G010007; No. LQ20G010001) and Ningbo Science and Technology Project (no. 2019C50008).

Conflicts of Interest: The authors declare that there is no conflict of interest regarding the publication of this paper.

\section{References}

1. Herrera, F.; Herrera-Viedma, E. Linguistic decision analysis: Steps for solving decision problems under linguistic information. Fuzzy Sets Syst. 2000, 115, 67-82. [CrossRef] 
2. Zadeh, L.A. Fuzzy sets. Inf. Control 1965, 18, 338-353. [CrossRef]

3. Atanassov, K. Intuitionistic fuzzy sets. Fuzzy Sets Syst. 1986, 20, 87-96. [CrossRef]

4. Torra, V. Hesitant fuzzy sets. Int. J. Intell. Syst. 2010, 25, 529-539. [CrossRef]

5. Yager, R.R. Pythagorean membership grades in multi-criteria decision making. IEEE Trans. Fuzzy Syst. 2014, 22, 958-965. [CrossRef]

6. Ye, J. Multicriteria decision-making method using the correlation coefficient under single-valued neutrosophic environment. Int. J. Gen. Syst. 2013, 42, 386-394. [CrossRef]

7. Yager, R.R. Generalized orthopair fuzzy sets. IEEE Trans. Fuzzy Syst. 2017, 25, 1222-1230. [CrossRef]

8. Ye, J. An extended TOPSIS method for multiple attribute group decision making based on single valued neutrosophic linguistic numbers. J. Intell. Fuzzy Syst. 2015, 28, 247-255. [CrossRef]

9. Jin, F.F.; Pei, L.D.; Chen, H.Y.; Langari, R.; Liu, J.P. A novel decision-making model with pythagorean fuzzy linguistic information measures and its application to a sustainable blockchain product assessment problem. Sustainability 2019, 11, 5630. [CrossRef]

10. Liu, P.D.; Wang, Y.M. Multiple attribute group decision making methods based on intuitionistic linguistic power generalized aggregation operator. Appl. Soft Comput. 2014, 17, 90-104. [CrossRef]

11. Guo, Z.X.; Sun, F.F. Multi-attribute decision making method based on single-valued neutrosophic linguistic variables and prospect theory. J. Intell. Fuzzy Syst. 2019, 37, 5351-5362. [CrossRef]

12. Zhao, S.P.; Wang, D.; Liang, C.Y.; Lu, W.X. Induced Choquet Integral aggregation operators with single-valued neutrosophic uncertain linguistic numbers and their application in multiple attribute group decision-making. Math. Probl. Eng. 2019. [CrossRef]

13. Ji, P.; Zhang, H.Y.; Wang, J.Q. Selecting an outsourcing provider based on the combined MABAC-ELECTRE method using single-valuedneutrosophic linguistic sets. Comput. Ind. Eng. 2018, 120, 429-441. [CrossRef]

14. Wang, J.Q.; Yang, Y.; Li, L. Multi-criteria decision-making method based on single-valued neutrosophic linguistic Maclaurin symmetric mean operators. Neural Comput. Appl. 2018, 30, 1529-1547. [CrossRef]

15. Chen, J.; Zeng, S.Z.; Zhang, C.H. An OWA distance-based, single-valued neutrosophic linguistic topsis approach for green supplier evaluation and selection in low-carbon supply chains. Int. J. Environ. Res. Public Health 2018, 15, 1439. [CrossRef]

16. Cao, C.D.; Zeng, S.Z.; Luo, D.D. A single-valued neutrosophic linguistic combined weighted distance measure and its application in multiple-attribute group decision-making. Symmetry 2019, 11, 275. [CrossRef]

17. Garg, H.; Nancy. Linguistic single-valued neutrosophic prioritized aggregation operators and their applications to multiple-attribute group decision-making. J. Ambient Intell. Humaniz. Comput. 2018, 9, 1975-1997. [CrossRef]

18. Merigó, J.M.; Palacios-Marqués, D.; Soto-Acosta, P. Distance measures, weighted averages, OWA operators and Bonferroni means. Appl. Soft Comput. 2017, 50, 356-366. [CrossRef]

19. Merigó, J.M.; Gil-Lafuente, A.M. New decision-making techniques and their application in the selection of financial products. Inf. Sci. 2010, 180, 2085-2094. [CrossRef]

20. Merigó, J.M.; Casanovas, M. Decision making with distance measures and linguistic aggregation operators. Int. J. Fuzzy Syst. 2010, 12, 190-198.

21. Merigó, J.M.; Casanovas, M. Decision making with distance measures and induced aggregation operators. Comput. Ind. Eng. 2011, 60, 66-76. [CrossRef]

22. Xian, S.D.; Sun, W.J.; Xu, S.H.; Gao, Y.Y. Fuzzy linguistic induced OWA Minkowski distance operator and its application in group decision making. Pattern Anal. Appl. 2016, 19, 325-335. [CrossRef]

23. Merigó, J.M.; Casanovas, M.; Zeng, S.Z. Distance measures with heavy aggregation operators. Appl. Math. Model. 2014, 38, 3142-3153. [CrossRef]

24. Zhou, L.G.; Xu, J.X.; Chen, H.Y. Linguistic continuous ordered weighted distance measure and its application to multiple attributes group decision making. Appl. Soft Comput. 2014, 25, 266-276. [CrossRef]

25. Zeng, S.Z.; Su, W.H. Intuitionistic fuzzy ordered weighted distance operator. Knowl. Based Syst. 2011, 24, 1224-1232. [CrossRef] 
26. Zeng, S.Z.; Xiao, Y. A method based on TOPSIS and distance measures for hesitant fuzzy multiple attribute decision making. Technol. Econ. Dev. Econ. 2018, 24, 969-983. [CrossRef]

27. Xu, Z.S.; Xia, M.M. Distance and similarity measures for hesitant fuzzy sets. Inf. Sci. 2011, 181, $2128-2138$. [CrossRef]

28. Qin, Y.; Liu, Y.; Hong, Z.Y. Multicriteria decision making method based on generalized Pythagorean fuzzy ordered weighted distance measures. J. Intell. Fuzzy Syst. 2017, 33, 3665-3675. [CrossRef]

29. Zeng, S.Z.; Chen, J.P.; Li, X.S. A hybrid method for pythagorean fuzzy multiple-criteria decision making. Int. J. Inf. Technol. Decis. Mak. 2016, 15, 403-422. [CrossRef]

30. Alfaro-García, V.G.; Merigó, J.M.; Gil-Lafuente, A.M.; Kacprzyk, J. Logarithmic aggregation operators and distance measures. Int. J. Intell. Syst. 2018, 33, 1488-1506. [CrossRef]

31. Zhou, L.; Chen, H.; Liu, J. Generalized logarithmic proportional averaging operators and their applications to group decision making. Knowl. Based Syst. 2012, 36, 268-279. [CrossRef]

32. Zhou, L.; Tao, Z.; Chen, H.Y.; Liu, J. Generalized ordered weighted logarithmic harmonic averaging operators and their applications to group decision making. Soft Comput. 2014, 19, 715-730. [CrossRef]

33. Alfaro-Garcia, V.G.; Merigo, J.M.; Plata-Perez, L.; Alfaro-Calderon, G.G.; Gil-Lafuente, A.M. Induced and logarithmic distances with multi-region aggregation operators. Technol. Econ. Dev. Econ. 2019, 25, 664-692. [CrossRef]

34. Smarandache, F. Neutrosophy, Neutrosophic Probability, Set, and Logic. Proquest Information E Learning; American Research Press: Ann Arbor, MI, USA, 1998.

35. $\mathrm{Xu}, \mathrm{Z}$.S. A note on linguistic hybrid arithmetic averaging operator in multiple attribute group decision making with linguistic information. Group Decis. Negot. 2006, 15, 593-604. [CrossRef]

36. Yager, R.R. On ordered weighted averaging aggregation operators in multi-criteria decision making. IEEE Trans. Syst. Man Cybern. B 1988, 18, 183-190. [CrossRef]

37. Zeng, S.Z.; Su, W.H.; Zhang, C.H. Intuitionistic fuzzy generalized probabilistic ordered weighted averaging operator and its application to group decision making. Technol. Econ. Dev. Econ. 2016, 22, 177-193. [CrossRef]

38. Yu, L.P.; Zeng, S.Z.; Merigo, J.M.; Zhang, C.H. A new distance measure based on the weighted induced method and its application to Pythagorean fuzzy multiple attribute group decision making. Int. J. Intell. Syst. 2019, 34, 1440-1454. [CrossRef]

39. Zeng, S.Z.; Peng, X.M.; Baležentis, T.; Streimikiene, D. Prioritization of low-carbon suppliers based on Pythagorean fuzzy group decision making with self-confidence level. Econ. Res. Ekon. Istraživanja 2019, 32, 1073-1087. [CrossRef]

40. Zeng, S.Z. Pythagorean fuzzy multiattribute group decision making with probabilistic information and OWA approach. Int. J. Intell. Syst. 2017, 32, 1136-1150. [CrossRef]

41. Merigó, J.M.; Yager, R.R. Generalized moving averages, distance measures and OWA operators. Int. J. Uncertain. Fuzziness Knowl. Based Syst. 2013, 21, 533-559. [CrossRef]

42. Garg, H.; Rani, D. Exponential, logarithmic and compensative generalized aggregation operators under complex intuitionistic fuzzy environment. Group Decis. Negot. 2019, 28, 991-1050. [CrossRef]

43. Rahman, K.; Abdullah, S. Some induced generalized interval-valued Pythagorean fuzzy Einstein geometric aggregation operators and their application to group decision-making. Comput. Appl. Math. 2019, 38, 139-154. [CrossRef]

44. Li, J.R.; Lu, H.X.; Zhu, J.L.; Wang, Y.B.; Li, X.P. Aquatic products processing industry in China: Challenges and outlook. Trends Food Sci. Technol. 2009, 20, 73-77. [CrossRef]

45. Zeng, S.Z.; Chen, S.M.; Kuo, L.W. Multiattribute decision making based on novel score function of intuitionistic fuzzy values and modified VIKOR method. Inf. Sci. 2019, 488, 76-92. [CrossRef]

46. Zhang, C.H.; Wang, Q.; Zeng, S.Z.; Balezentis, T.; Streimikiene, D.; Alisauskaite-Seskiene, I.; Chen, X. Probabilistic multi-criteria assessment of renewable micro-generation technologies in households. J. Clean. Prod. 2019, 212, 582-592. [CrossRef]

47. Balezentis, T.; Streimikiene, D.; Melnikienè, R.; Zeng, S.Z. Prospects of green growth in the electricity sector in Baltic States: Pinch analysis based on ecological footprint. Resour. Conserv. Recycl. 2019, 142, 37-48. [CrossRef]

48. Luo, D.D.; Zeng, S.Z.; Chen, J. A probabilistic linguistic multiple attribute decision making based on a new correlation coefficient method and its application in hospital assessment. Mathematics 2020, 8, 340. [CrossRef] 
49. Zhang, C.H.; Chen, C.; Streimikiene, D.; Balezentis, T. Intuitionistic fuzzy multimoora approach for multi-criteria assessment of the energy storage technologies. Appl. Soft Comput. 2019, 79, 410-423. [CrossRef]

50. Jin, H.H.; Ashraf, S.; Abdullah, S.; Qiyas, M.; Bano, M.; Zeng, S.Z. Linguistic spherical fuzzy aggregation operators and their applications in multi-attribute decision making problems. Mathematics 2019, 7, 413. [CrossRef] 